\title{
EFFECTS OF LAND USE FEATURES IN BLOCKS ON THE SELECTION OF LOW-CARBON TRAVEL BY URBAN RESIDENTS
}

\author{
LI, L. ${ }^{1}-$ ZHANG, X. ${ }^{2}-$ ZHANG, X. Q. ${ }^{1}-$ Hou, Q. H. ${ }^{1 *}-$ LUO, X. Q. ${ }^{1}$ \\ ${ }^{1}$ School of Architecture, Chang'an University, Shanxi 710061, China \\ ${ }^{2}$ Pomegranate Group, Fengtai District, Beijing 10071, China \\ *Corresponding author \\ e-mail: houquanhua@chd.edu.cn
}

(Received $3^{\text {rd }}$ Apr 2019; accepted $17^{\text {th }}$ May 2019)

\begin{abstract}
This paper attempts to disclose the effects of land use pattern on the selection of low-carbon travel by urban residents. Targeting 19 blocks in north western China's Xi'an, the author collected data from various sources, including phone signals, app records and field surveys, and divided the blocks into two groups based on the difference in land use pattern. The multi-source data ensures the objectivity and accuracy of the analysis. Then, the relationship models between block land use features and residents' travel methods were established based on the Logit model, and the effects of six land use features on the selection of low-carbon travel were discussed in detail. The research results show a strong correlation between land use pattern and travel mode of the residents in the 19 blocks; the six land use features have different impacts on the travel mode; the residents in the two types of blocks prefer different low-carbon travel methods. This research lays a scientific basis for the optimization of urban space and land use. Keywords: green and low-carbon, travel methods, Logit model, land use characteristics, city blocks
\end{abstract}

\section{Introduction}

The travel frequency and range of urban residents are affected by the land use pattern. In fact, the residents mainly consider two factors when choosing between different travel methods, namely, their own needs (e.g. work, shopping and entertainment) and the land use features (e.g. form, intensity and function). To encourage low-carbon travel, it is necessary to disclose the effects of land use features on travel mode and identify the control indices of intensive land use in blocks, which are the basic units of the urban area. In this way, more residents will choose lowcarbon travel, reducing the carbon emissions in transport and protecting the environment (Tu and Ma, 2018).

The studies on land use pattern generally hold that dense grids and small roads are conducive to low-carbon travel among residents (Friedman and Cammalleri, 1994; Liu and Qing, 2011; Susan, 1996; Newman and Kenworthy; 1996; Hou et al., 2018; Zhang et al., 2018; Pan, 2010). Some scholars compared the effects of different block types on residents' low-carbon travel, including traditional hutongs, dense square grids, neighborhood units, and superblocks, and concluded that the residents are more likely to adopt low-carbon travel in traditional hutongs and dense square grids (Qin and Tian, 2013; Huang et al., 2013; Chai et al., 2011). However, there is not yet an agreement on the spacing in the road network. Atash (1994) suggested that most residents prefer walking over driving if the destination is $400 \mathrm{~m}$ away or within $5 \mathrm{~min}$ drive, while Xiao (2011) claimed that most people are willing to walk to a destination within $150 \mathrm{~m}$. 
On land use intensity, many scholars have found that high residential density suppresses car usage, travel frequency and commuting distance, while promoting nonmotorized travel (Hou and Wang, 2016; Forsyth et al., 2007; Handy, 1992; Giuliaono. and Naravan, 2003; Levinson and Kumar, 1997). Compared to rural areas, the urban area has a large population and a high plot ratio. Thus, the travel demand of urban residents is more sensitive to the changes in land use than that of rural residents. Facing the mixture of various types of land use, the urban residents often choose to travel on foot or bike within a small range (Zhou and Yang, 2005). Some scholars noted that the plot ratio has a positive impact on traffic flow intensity, and thus promotes public transport among urban residents (Caldera et al., 2017; Mao et al., 2004, 2005, 2002).

On land use function, the degree of mixed land use is positively correlated with the ratio of public transport and walking (Frank and Pivo, 1994; Friedman et al., 1994; Kockelman, 1997; Ewing and Fanag, 2008; Greenwald and Boarnet, 2002), and that of walking and biking (Zhou and Qian, 2014; Wang and Chai, 2009; Pan et al., 2009; Ma et al., 2013, 2011). In addition, it is often believed that the urban residents' choice between travel methods depends heavier on the degree of mixed land use in the workplace than that in residential areas (Ewing et al., 2003; Maat and Timmermans, 2009). However, some scholars argued that the degree of mixed land use has little effect on the choice of travel methods (Liu et al., 2010; Cervero, 1995). Moreover, many scholars held that the balance between working function and residential function of land use will shorten the commuting time and increase the ratio of walking and biking (Cervero, 1989; Long et al., 2012; Tana et al., 2015). The travel features of residents can be judged more clearly with land use function data from multiple sources (Long et al., 2012; Hou et al., 2018, 2017).

In view of the above, this paper attempts to disclose the relationship between lowcarbon travel and block land use using multi-source data on various transport modes, and clarify the influence mechanism of land use on low-carbon travel through qualitative and quantitative analyses. With the aid of big data technology, the spatiotemporal features of low-carbon travel were discussed in the context of land use, and determined in an objective and scientific manner. The research findings shed new light on the optimization of block structure, enrich theories and methods of block land use, and promote low-carbon travel among urban residents.

\section{Methodology}

\section{Background}

\section{(1) Research object}

The existing studies have shown that the urban residents' selection of travel methods, and their carbon emissions in travel, are greatly affected by the intensity, form and function of land use. Thus, the three land use indices of blocks must be arranged in a scientific manner. Based on the geographic information system (GIS), this paper selects 19 blocks from Xi'an, the seat of northwestern China's Shaanxi Province, and divides them into two groups by land use function. As shown in Figure 1, the blocks $a, b, e, h, l, n, o, q$ and $r$ were categorized as housing-oriented blocks, because more than half of the land in each of them is used for residential purpose; the blocks $c, d, f, g, i, j, k, m, p$ and $s$ were classified as job-oriented blocks, because more than half of the land in each of them is used for working purpose. 


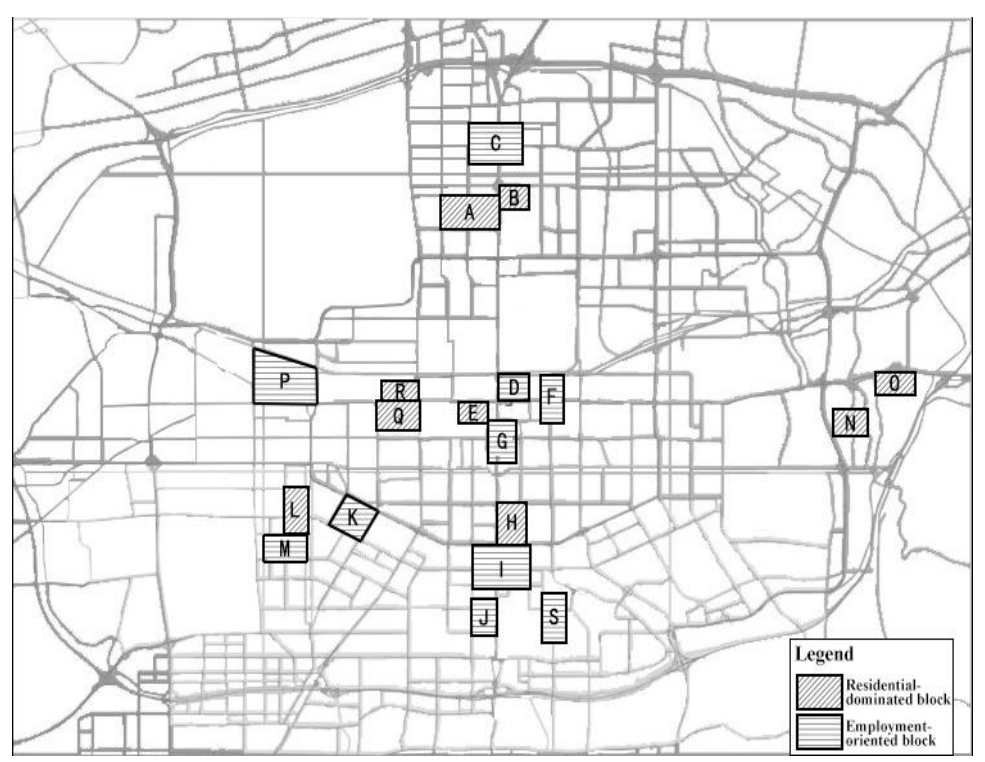

Figure 1. Classification of the target blocks

\section{(2) Data on residents' travel}

The data on residents' travel data (e.g. distance, frequency, trajectory and mode) were extracted from phone signals, app records and field surveys in the two weeks from Nov. 5 18, 2018. Specifically, the phone signals were acquired from China Unicom, the service provider to $17.07 \%$ of all phone users in Shaanxi; the app records were obtained from the GPS data in the bike sharing app Mobike; the field surveys were carried out in the 18 blocks to verify the results of phone signals and app records, collecting 1,900 data entries.

\section{(3) Data on land use}

The data on land use were obtained from digital maps, satellite images and phone signals. The digital maps were adopted to determine the nature of land use in each block, and verified against the remote-sensing satellite images. The residential and working situation were evaluated using the phone signals.

\section{Index preparation}

In this paper, the land use indices that greatly affect low-carbon travel are determined in three steps: quantifying the land use features, selecting the features related to travel mode through Pearson correlation analysis, and evaluating the relationship between feature indices and low-carbon travel by the Logit model. The specific process is explained as follows.

\section{(1) Feature indices of land use}

Inspired by the existing studies, six feature indices about land use function, intensity and form were found to be highly relevant to how urban residents choose between travel methods. The six indices are the degree of mixed land use, the job-housing ratio, building density, plot ratio, road density and the ratio of open space.

The degree of mixed land use $M$ can be calculated as: 


$$
M=-\sum_{i}\left[\left(\frac{b_{i}}{a}\right) \ln \left(\frac{b_{i}}{a}\right)\right]
$$

where $a$ is the total area of all types of buildings in a block $\left(\mathrm{m}^{2}\right) ; b$ is the area of type $i$ buildings in the block $\left(\mathrm{m}^{2}\right)$.

The job-housing ratio $J H R$ can be calculated as:

$$
J H R=\frac{J_{i}}{H_{i}}
$$

where $J H R_{i}$ is the job-housing ratio of block $i ; I_{i}$ is the number of jobs in block $\mathrm{i} ; H_{i}$ is the resident population in block i.

The building density $B$ can be calculated as:

$$
B=\frac{S_{f}}{L}
$$

where $S_{f}$ is the floor area of all buildings in a block $\left(\mathrm{m}^{2}\right) ; L$ is total land area in the block $\left(\mathrm{m}^{2}\right)$.

The plot ratio $P$ can be calculated as:

$$
P=\frac{S_{a}}{L}
$$

where $\mathrm{S}_{\mathrm{a}}$ is the total building area of a block $\left(\mathrm{m}^{2}\right) ; L$ is total land area in the block $\left(\mathrm{m}^{2}\right)$.

The road density $\rho$ can be calculated as:

$$
\rho=\left(\sum_{i} l_{i}\right) / L
$$

where $\mathrm{L}_{\mathrm{i}}$ is the length of road $i$ in a block; $L$ is total land area in the block $\left(\mathrm{m}^{2}\right)$.

The ratio of open space $O$ can be calculated as:

$$
o=\frac{S_{g}}{L}
$$

where $\mathrm{S}_{\mathrm{g}}$ is the area of public green space in a block $\left(\mathrm{m}^{2}\right) ; L$ is total land area in the block $\left(\mathrm{m}^{2}\right)$.

\section{(2) Pearson correlation analysis}

The Pearson correlation analysis was performed on SPSS, aiming to clarify how different land use features are correlated to each other and select the features that are relevant to low-carbon travel. 


\section{(3) Logit model analysis}

Taking the total population of each block as the behavioral decision unit, the optimal travel mode will be selected by the block residents from a set of independent alternatives. Hence, the Logit model was selected to determine the relationship between typical land use features and low-carbon travel.

Let $U_{\text {in }}$ be the utility of choosing travel mode $i$ from the set of alternatives $C_{\mathrm{n}}$ in block $n$, that is, the effect of land use features on the travel mode selection of the residents in the block. When two alternatives $i$ and $j$ are available $\left(i, j \in C_{n}\right.$ and $i \neq j$ ), the residents of block $n$ will select travel mode $i$ only if $U_{i n}$ is greater than $U_{j n}$. According to the random utility theory, $U_{\text {in }}$ can be expressed as:

$$
U_{i n}=V_{i n}+\varepsilon_{i n}
$$

where $V_{\text {in }}$ is utility constant when travel mode $i$ is selected for block $n$; $\varepsilon_{\text {in }}$ is the change in utility probability resulted from the implicit preference unique to the block residents.

If $\varepsilon_{\text {in }}$ and $V_{\text {in }}$ are independent of each other and $\varepsilon_{\text {in }}$ obeys the Gumbel distribution, then the probability that the block residents choose travel mode $i$ can be described as:

$$
P_{i n}=\frac{\exp \left(\lambda V_{i n}\right)}{\sum_{j \in c_{n}-i} \exp \left(\lambda V_{i n}\right)}
$$

Next, the utility constant when travel mode $i$ is selected for block $n\left(V_{\text {in }}\right)$ can be described by the following linear function:

$$
V_{i n}=\sum_{k} \beta_{k i n} \chi_{k i n}
$$

where $x_{\text {kin }}$ is the $k$-th land use index when selected travel mode $i$ is selected for block $n ; \beta_{\text {kin }}$ is the undetermined coefficient of $x_{\text {kin }}$. The value of $\beta_{\text {kin }}$ can be calibrated by survey data. Taking the logarithm on both sides of Equation 9, the contribution rates of six different travel methods $P_{\text {in }}$ (i.e. walking, bike, e-bike, motorcycle, bus, metro, car) can be expressed as:

$$
\ln \left(P_{i n}\right)=\lambda \sum_{k} \beta_{k i n} \chi_{k i n}-\ln \left[\sum_{j \in c_{n}-i} \exp \left(\lambda \sum_{k} \beta_{k j n} \chi_{k j n}\right)\right]
$$

where the terms on the right side are the utility functions of the six travel methods. Based on the features of the research data, a multiple linear regression model can be established to describe the impacts of land use features on residents' travel mode:

$$
y_{\text {in }}=\ln \left(p_{\text {in }}\right)=\beta_{\text {oin }}+\sum_{k} \beta_{k i n} \chi_{\text {kin }}+\epsilon_{\text {in }}
$$

where $y_{\text {in }}$ is the logarithm of the current sharing rate of the six travel methods; $x_{\text {in }}$ is an explanatory variable with the same meaning above; $\beta_{\text {oin }}$ and $\beta_{\text {kin }}$ are regression 
coefficients; $\epsilon_{\text {in }}$ is a random parameter. Obviously, the regression coefficient $\beta_{\text {oin }}$ satisfies:

$$
\beta_{\mathrm{oin}}=-\ln \left[\sum_{j \in c_{n}-i} \exp \left(\lambda \sum_{k} \beta_{k j n} \chi_{k j n}\right)\right]
$$

The equation is clearly workable.

\section{Results}

\section{Features of residents' travel mode and land use}

As mentioned before, the blocks $a, b, e, h, l, n, o, q$ and $r$ were categorized as housing-oriented blocks, and the blocks $c, d, f, g, i, j, k, m, p$ and $s$ were classified as job-oriented blocks.

\section{(1) Low-carbon travel features of residents}

The research data show that the residents in the 19 blocks mainly travel by walking, bike, e-bike, motorcycle, bus, metro and car.

The traffic flow in the housing-oriented blocks is relatively low, and dominated by walking and bike. By contrast, the job-oriented blocks have a high traffic flow, most of which occurs on bus and subway.

The residents in blocks $a, b, e, n, o, l$ and $m$ often engage in short-distance travels $(<1.5 \mathrm{~km}$ ), those in blocks $d, f, g, h, i, j, k, l, m, n, q, r$ and $s$ are frequently involved in mid-distance travels $(1.5 \sim 3 \mathrm{~km})$, and those in blocks $m$ and $p$ mainly travel over long distances $(3 \sim 21 \mathrm{~km})$. The residents in block $c$ have equal probability to embark on short-, mid- and long-distance travels.

The ratio of each low-carbon travel mode is listed in Table 1.

Table 1. The ratio of each low-carbon travel mode

\begin{tabular}{c|c|c|c|c|c|c}
\hline \multirow{2}{*}{$\begin{array}{c}\text { Block } \\
\text { name }\end{array}$} & \multicolumn{7}{|c}{ Travel mode } \\
\cline { 2 - 7 } & Pedestrian & Bicycle & $\begin{array}{c}\text { Electric bicycle or } \\
\text { motorcycle }\end{array}$ & $\begin{array}{c}\text { Conventional public } \\
\text { transportation }\end{array}$ & Metro & Car \\
\hline A & $6.84 \%$ & $4.94 \%$ & $5.19 \%$ & $16.42 \%$ & $17.19 \%$ & $49.41 \%$ \\
B & $18.53 \%$ & $7.13 \%$ & $8.62 \%$ & $15.35 \%$ & $15.34 \%$ & $35.02 \%$ \\
C & $17.10 \%$ & $16.51 \%$ & $11.93 \%$ & $15.52 \%$ & $13.12 \%$ & $25.82 \%$ \\
D & $15.24 \%$ & $5.65 \%$ & $7.69 \%$ & $15.76 \%$ & $37.33 \%$ & $18.33 \%$ \\
E & $37.75 \%$ & $15.35 \%$ & $25.20 \%$ & $9.47 \%$ & $5.18 \%$ & $7.06 \%$ \\
F & $15.04 \%$ & $27.45 \%$ & $25.26 \%$ & $9.80 \%$ & $13.42 \%$ & $9.03 \%$ \\
G & $22.43 \%$ & $3.63 \%$ & $5.49 \%$ & $19.94 \%$ & $33.32 \%$ & $15.19 \%$ \\
H & $12.21 \%$ & $2.67 \%$ & $6.80 \%$ & $17.40 \%$ & $39.08 \%$ & $21.84 \%$ \\
I & $4.75 \%$ & $1.68 \%$ & $3.26 \%$ & $16.30 \%$ & $55.34 \%$ & $18.67 \%$ \\
J & $29.80 \%$ & $36.20 \%$ & $11.93 \%$ & $2.53 \%$ & $12.62 \%$ & $6.93 \%$ \\
K & $10.04 \%$ & $14.75 \%$ & $20.25 \%$ & $8.70 \%$ & $15.02 \%$ & $31.24 \%$ \\
L & $21.85 \%$ & $13.38 \%$ & $10.50 \%$ & $8.61 \%$ & $10.13 \%$ & $35.53 \%$ \\
M & $13.13 \%$ & $8.94 \%$ & $22.52 \%$ & $25.48 \%$ & $9.19 \%$ & $20.74 \%$ \\
N & $31.16 \%$ & $9.40 \%$ & $16.38 \%$ & $16.38 \%$ & $11.13 \%$ & $15.56 \%$ \\
O & $27.43 \%$ & $22.01 \%$ & $8.85 \%$ & $14.51 \%$ & $11.62 \%$ & $15.58 \%$ \\
\hline
\end{tabular}




\begin{tabular}{l|c|c|c|c|c|c}
\hline $\mathrm{P}$ & $22.63 \%$ & $12.61 \%$ & $21.55 \%$ & $10.02 \%$ & $12.31 \%$ & $20.87 \%$ \\
$\mathrm{Q}$ & $20.14 \%$ & $22.62 \%$ & $12.02 \%$ & $13.26 \%$ & $13.55 \%$ & $18.41 \%$ \\
$\mathrm{R}$ & $16.96 \%$ & $27.33 \%$ & $16.20 \%$ & $8.65 \%$ & $11.27 \%$ & $19.58 \%$ \\
$\mathrm{~S}$ & $6.67 \%$ & $1.22 \%$ & $3.47 \%$ & $30.82 \%$ & $19.28 \%$ & $38.55 \%$ \\
\hline
\end{tabular}

\section{(2) Land use features of the blocks}

Based on the six feature indices (Eqs. 1-6), the land use features of the 19 blocks were obtained in the aspects of function, intensity and form. The results are displayed in Table 2.

Table 2. The land use features of the blocks

\begin{tabular}{c|c|c|c|c|c|c|c|c}
\hline $\begin{array}{c}\text { Block } \\
\text { name }\end{array}$ & $\begin{array}{c}\text { Land } \\
\text { area } \\
(\mathbf{h a})\end{array}$ & $\begin{array}{c}\text { Building } \\
\text { area } \\
\left(\mathbf{1 0}^{\mathbf{4}} \mathbf{m}^{\mathbf{2}}\right)\end{array}$ & $\begin{array}{c}\text { Building } \\
\text { density } \\
(\boldsymbol{\%})\end{array}$ & $\begin{array}{c}\text { Floor } \\
\text { area } \\
\text { ratio }\end{array}$ & $\begin{array}{c}\text { Building } \\
\text { mixing } \\
\text { degree }\end{array}$ & $\begin{array}{c}\text { Density of } \\
\text { road } \\
\text { network } \\
\left(\mathbf{k m}^{\mathbf{k}} \mathbf{\text { km }}\right)\end{array}$ & $\begin{array}{c}\text { Open space } \\
\text { proportion } \\
(\boldsymbol{\%})\end{array}$ & $\begin{array}{c}\text { Employment- } \\
\text { housing ratio }\end{array}$ \\
\hline $\mathrm{A}$ & 35.99 & 77.54 & 26.07 & 2.15 & 1.38 & 6.791 & 8.2 & 0.254 \\
$\mathrm{~B}$ & 21.99 & 14.97 & 21.45 & 0.68 & 0.69 & 8.844 & 4.02 & 0.597 \\
$\mathrm{C}$ & 161.52 & 121.77 & 13.99 & 0.75 & 1.86 & 6.165 & 24.43 & 0.518 \\
$\mathrm{D}$ & 26.83 & 49.99 & 34.97 & 1.86 & 1.45 & 10.324 & 8.72 & 0.647 \\
$\mathrm{E}$ & 10.28 & 21.55 & 62.58 & 2.1 & 0.91 & 16.476 & 0 & 0.312 \\
$\mathrm{~F}$ & 56.38 & 131.62 & 39.53 & 2.33 & 1.54 & 14.056 & 6.72 & 1.22 \\
$\mathrm{G}$ & 55.19 & 122.31 & 42.17 & 2.22 & 1.96 & 11.732 & 6.62 & 1.3 \\
$\mathrm{H}$ & 77.36 & 252.47 & 31.83 & 3.26 & 0.69 & 7.466 & 0.65 & 0.592 \\
$\mathrm{I}$ & 53.29 & 103.02 & 30.92 & 1.93 & 1.73 & 7.492 & 4.79 & 0.79 \\
$\mathrm{~J}$ & 42.24 & 80.63 & 35.62 & 1.91 & 1.58 & 7.838 & 5.42 & 0.36 \\
$\mathrm{~K}$ & 47.07 & 112.3 & 27.44 & 2.39 & 1.22 & 12.344 & 13.26 & 1.579 \\
$\mathrm{~L}$ & 79.63 & 133.21 & 18.43 & 1.67 & 0.82 & 7.946 & 3.91 & 0.322 \\
$\mathrm{M}$ & 77.48 & 70.08 & 25.39 & 0.9 & 0.97 & 6.899 & 3.85 & 0.456 \\
$\mathrm{~N}$ & 33.2 & 32.9 & 37.85 & 0.99 & 1.49 & 4.939 & 2.26 & 0.348 \\
$\mathrm{O}$ & 36.22 & 54.14 & 23 & 1.49 & 0.8 & 5.794 & 10.49 & 0.218 \\
$\mathrm{P}$ & 252.46 & 400 & 33.91 & 1.58 & 1.55 & 4.241 & 2.37 & 0.217 \\
$\mathrm{Q}$ & 79.83 & 176.34 & 33.26 & 2.21 & 1.32 & 6.848 & 5.16 & 0.425 \\
$\mathrm{R}$ & 38 & 60.41 & 34.17 & 1.59 & 1.25 & 10.358 & 17.17 & 0.672 \\
$\mathrm{~S}$ & 63.88 & 83.1 & 29.65 & 1.3 & 1.79 & 11.679 & 30.93 & 0.863 \\
\hline
\end{tabular}

\section{Correlation analysis}

\section{(1) Correlation between travel methods and land use features}

The correlation analysis between travel methods and land use features was carried out and the results were presented in the form of a matrix (Table 3). As shown in Table 3, the building density has a positive impact on the ratio of walking (significance $<0.05$ ) and a negative impact on the ratio of car travel (significance $<0.01$ ). The metro travel enjoys a significant positive correlation with plot ratio and degree of mixed land use $(0.05<$ significance $<0.1)$. In addition, the six travel methods have unobvious correlations with job-housing ratio, road density and ratio of open space. 
Table 3. Correlation matrix between travel methods and land use features

\begin{tabular}{|c|c|c|c|c|c|c|c|}
\hline & & $\begin{array}{l}\text { Building } \\
\text { mixing } \\
\text { degree }\end{array}$ & $\begin{array}{l}\text { Employment- } \\
\text { housing ratio }\end{array}$ & $\begin{array}{c}\text { Building } \\
\text { density }\end{array}$ & $\begin{array}{l}\text { Floor } \\
\text { area } \\
\text { ratio }\end{array}$ & $\begin{array}{c}\text { Road } \\
\text { network } \\
\text { density }\end{array}$ & $\begin{array}{l}\text { Open space } \\
\text { proportion }\end{array}$ \\
\hline \multirow{2}{*}{ Pedestrian } & $\begin{array}{c}\text { Pearson } \\
\text { correlation }\end{array}$ & -.187 & -.426 & $.479^{*}$ & -.142 & .042 & -.404 \\
\hline & $\begin{array}{l}\text { Significant } \\
\text { (two-tailed) }\end{array}$ & .442 & .069 & .038 & .563 & .863 & .086 \\
\hline \multirow{2}{*}{ Bicycle } & $\begin{array}{c}\text { Pearson } \\
\text { correlation }\end{array}$ & .072 & -.112 & .102 & .017 & .068 & .002 \\
\hline & $\begin{array}{c}\text { Significant } \\
\text { (two-tailed) }\end{array}$ & .770 & .648 & .677 & .944 & .782 & .992 \\
\hline \multirow{2}{*}{$\begin{array}{l}\text { Electric bicycle } \\
\text { or motorcycle }\end{array}$} & $\begin{array}{c}\text { Pearson } \\
\text { correlation }\end{array}$ & -.211 & .033 & .388 & -.050 & .278 & -.268 \\
\hline & $\begin{array}{c}\text { Significant } \\
\text { (two-tailed) }\end{array}$ & .385 & .893 & .101 & .839 & .248 & .268 \\
\hline \multirow{2}{*}{$\begin{array}{l}\text { Conventional } \\
\text { public } \\
\text { transportation }\end{array}$} & $\begin{array}{c}\text { Pearson } \\
\text { correlation }\end{array}$ & -.046 & .101 & -.190 & -.270 & -.079 & .366 \\
\hline & $\begin{array}{l}\text { Significant } \\
\text { (two-tailed) }\end{array}$ & .852 & .680 & .436 & .264 & .749 & .123 \\
\hline \multirow{2}{*}{ Subway } & $\begin{array}{c}\text { Pearson } \\
\text { correlation }\end{array}$ & .391 & .318 & .004 & .395 & -.026 & -.077 \\
\hline & $\begin{array}{l}\text { Significant } \\
\text { (two-tailed) }\end{array}$ & .098 & .184 & .987 & .094 & .916 & .753 \\
\hline \multirow{2}{*}{ Car } & $\begin{array}{c}\text { Pearson } \\
\text { correlation }\end{array}$ & -.203 & -.011 & $-.616^{* *}$ & -.171 & -.199 & .369 \\
\hline & $\begin{array}{l}\text { Significant } \\
\text { (two-tailed) }\end{array}$ & .404 & .966 & .005 & .483 & .414 & .120 \\
\hline
\end{tabular}

*At the 0.05 level (dual side), the correlation is significant

**At the 0.01 level (both sides), the correlation is significant

\section{(2) Correlation between land use features}

The correlation analysis shows no correlation between the three land use features that are significantly correlated to the selection of travel mode (Table 4).

Table 4. Correlation matrix between land use features

\begin{tabular}{c|c|c|c|c}
\hline \multicolumn{2}{l|}{} & $\begin{array}{c}\text { Building } \\
\text { mixing degree }\end{array}$ & $\begin{array}{c}\text { Building } \\
\text { density }\end{array}$ & $\begin{array}{c}\text { Floor area } \\
\text { ratio }\end{array}$ \\
\hline \multirow{2}{*}{ Building mixing degree } & Pearson correlation & 1 & .127 & .022 \\
& Significant (two-tailed) & & .603 & .929 \\
\hline \multirow{2}{*}{ Building density } & Pearson correlation & .127 & 1 & .408 \\
& Significant (two-tailed) & .603 & & .083 \\
\hline \multirow{2}{*}{ Floor area ratio } & Pearson correlation & .022 & .408 & 1 \\
& Significant (two-tailed) & .929 & .083 & \\
\hline
\end{tabular}

**At the 0.01 level (two-tailed), the correlation is significant 


\section{Relationship models between land use features and low-carbon travel}

The logit model (Eqs. 7-12) can be used to calculate the correlation between land use characteristics and low-carbon travel characteristics in different types of blocks.

\section{(1) The relationship model for housing-oriented blocks}

Based on the results of regression analysis the relationship models between land use features and low-carbon travel in housing-oriented blocks can be constructed as:

$$
\begin{gathered}
y_{11}=-0.894+0.00592 z_{1}-0.0677 z_{2}+0.00192 z_{3}+0.0352 z_{4}-0.00296 z_{5}+0.00867 z_{6} \\
y_{12}=-0.98-0.0233 z_{1}+0.0444 z_{2}-0.0171 z_{4}-0.001 z_{5}-0.0125 z_{6} \\
y_{13}=-1.158+0.0062 z_{1}+0.0122 z_{2}-0.0269 z_{4}+0.0136 z_{5}-0.016 z_{6} \\
z_{1}=\frac{x_{1}^{2}}{100}, z_{2}=\frac{x_{2}^{3}}{10000}, z_{3}=\frac{x_{3}^{3}}{10000}, z_{4}=\frac{x_{4}^{3}}{10000}, z_{5}=\frac{x_{5}^{2}}{100}, z_{6}=x_{6}
\end{gathered}
$$

where $y_{\text {in }}$ is the probability logarithm of block $i$ to choose travel mode $n$ ( $i=1$ for housing-oriented blocks; $i=2$ for job-oriented blocks; $n=1$ for zero-carbon travel methods like walking and bike; $n=2$ for high-carbon travel methods like e-bike, motorcycle and car; $n=3$ for low-carbon travel methods like bus and metro); $x_{j}$ is the standardized value of land use index $j$ ( $j=1$ for building density; $j=2$ for plot ratio; $j=3$ for the degree of mixed land use; $j=4$ for road density; $j=5$ for the ratio of open space; $j=6$ for job-housing ratio).

\section{(2) The relationship model for job-oriented blocks}

Based on the results of regression analysis, the relationship models between land use features and low-carbon travel in job-oriented blocks can be constructed as:

$$
\begin{gathered}
y_{21}=-0.262-0.149 z_{1}-0.253 z_{2}+0.0383 z_{3}+0.091 z_{4}-0.0231 z_{5}+0.0426 z_{6} \\
y_{22}=-1.339+0.336 z_{2}-0.0604 z_{3}-0.111 z_{4}+0.0221 z_{5}-0.0525 z_{6} \\
y_{23}=-2.201-0.0083 z_{1}+0.0543 z_{2}+0.0422 z_{3}+0.0474 z_{4}+0.00071 z_{5}-0.0149 z_{6}
\end{gathered}
$$

where the symbols have the same meanings as above.

\section{Discussion}

The traffic flow is essential to the research on the travel features of urban residents. The phone signals can accurately reflect the traffic flows of travel methods like car, bus and metro. However, it is difficult to obtain the complete traffic flows of walking and bike from phone signals, due to the long intervals between two collections. Thus, the 
records of Mobike and field survey data were necessary for correction of the data acquired from phone signals.

The nature of land use has a great impact on the traffic flow and ratio of each travel mode. For instance, the residential-oriented blocks have a far smaller traffic flow than the job-oriented ones. In general, the residential-oriented blocks are dominated by nonmotorized travel while the job-oriented blocks are dominated by motorized travel.

In residential-oriented blocks (Eqs. 13-16), building density promotes the ratio of zero- and low-carbon travel methods and inhibits that of high-carbon travel methods; the plot ratio suppresses the ratio of zero-carbon travel methods, but promotes that of high- and low-carbon travel methods; the degree of mixed land use improves the ratio of zero-carbon travel methods, with no significant impact on high- and low-carbon travel methods; road density has a positive impact on the ratio of zero-carbon travel methods, and a negative impact on low- and high-carbon travel methods; the ratio of open space reduces the ratio of zero- and high-carbon travel methods, yet increases the ratio of low-carbon travel methods; the job-housing ratio enhances the ratio of zerocarbon travel methods, and lowers the ratio of high- and low-carbon travel methods.

In job-oriented blocks (Eqs. 17-19), building density has an unobvious effect on the ratio of high-carbon travel methods; the plot ratio promotes the ratio of high- and lowcarbon travel methods; the degree of mixed land use and road density both elevate the ratio of zero- and low-carbon travel methods, and reduce that of high-carbon travel methods; the ratio of open space inhibits the ratio of zero-carbon travel methods, but promotes the ratio of low- and high-carbon travel methods; the job-housing ratio has a positive effect on the ratio of zero-carbon travel methods and an inhibiting effect on the ratio of high- and low-carbon travel methods.

\section{Conclusions}

The previous studies on the effect of land use pattern on residents' travel mode are highly subjective due to the difficulty in data acquisition, failing to verify their theoretical hypotheses. This paper objectively demonstrates how land use features affect the low-carbon travel among urban residents. The research data were collected from various sources, including phone signals, app records and field surveys, making it possible to analyze and verify the effects in an objective manner. Two models were established to depict the relationship between block land use features and residents' travel methods, and the effects of six land use features on the selection low-carbon travel were discussed in details. The main conclusions are as follows.

The nature of land use has a great impact on the traffic flow and ratio of each travel mode. In other words, the land use pattern is a significant determinant of the travel features of urban residents.

The residential-oriented blocks feature high building density, low plot ratio, high degree of mixed land use, low ratio of open space and high job-housing ratio. The residents in these blocks prefer non-motorized, low-carbon travel methods. By contrast, the job-oriented blocks have low building density, high plot ratio, high degree of mixed land use, medium road density, high ratio of open space and low job-housing ratio. The residents in these blocks are used to public travel methods.

The future research will further eliminate the errors in feature extraction, widen the scope of research area, and simplify the index system. 
Acknowledgements. The research of this paper was funded by Shaanxi natural science basic research project (No.2017jm5124) and Shaanxi science and technology plan project (No.2017jm5124) "soft science research plan" general project (No.2017jm5124). Research project on major theoretical and practical issues in social science of Shaanxi province in 2018 (No.2018z026, 2018Z026), The Soft Science Program of the Ministry of Housing and urban-rural Development (No. 2016-k2-020), special fund for basic research operating expenses of central universities (No.310841172001, 300102418101).

\section{REFERENCES}

[1] Atash, F. (1994): Redesigning suburbia for walking and transit: emerging concepts. Urban Planning and Development 120(1): 48-57.

[2] Caldera, M., Puglisi, G., Zanghirella, F., Margiotta, F., Ungaro, P., Talucci, V., Cammarata, G. (2017): Proposal of a survey-based methodology for the determination of the energy consumption in the residential sector. - International Journal of Heat and Technology 35(S1): S152-S158.

[3] Cervero, R. (1989): Jobs-housing balancing and regional mobility. - Journal of the American Planning Association 55(2): 136-150.

[4] Cervero, R. (1995): Planned communities, self-containment and commuting: a crossnational perspective. - Urban Studies 32(7): 1135-1161.

[5] Chai, Y. W., Xiao, Z. P., Liu, Z. L. (2011): Comparative analysis on CO2 emission per household in daily travel based on spatial behavior constraints. - Scientia Geographica Sinica 31(7): 843-849.

[6] Ewing, R., Fang, R. (2008): The impact of urban form on U.S. residential energy use. Housing Policy Debate 19(1): 1-30.

[7] Ewing, R., Pendall, R., Chen, D. (2003): Measuring sprawl and its transportation impacts. - Transportation Research Record: Journal of the Transportation Research Board 1831(1): 175-183.

[8] Forsyth, A., Oakes, J. M., Schmitz, K. H. (2007): Does residential density increase walking and other physical activity. - Urban Studies 44(4): 679-697.

[9] Frank, L. D., Pivo, G. (1994): Impacts of mixed use and density on utilization of three modes of travel: single-occupant vehicle, transit and walking. - Transportation Research Record 1466: 44-52.

[10] Friedman, A., Cammalleri, V. (1994): Reducing energy, resources and construction waste through effective residential unit design. - Building Research and Information 22(2): 103-108.

[11] Friedman, B., Gordon, S. P., Peers, J. B. (1994): The effect of neo-traditional neighborhood design on travel characteristics. - Transportation Research Record 1400: 63-70.

[12] Giuliaono, G., Naravan, D. (2003): Another look at travel patterns and urban form the US and Great Britain. - Urban Studies 40(11): 2295-2312.

[13] Greenwald, M. J., Boarnet, M. G. (2002): The built environment as a determinant of walking behavior: analyzing non-work pedestrian travel in Portland, Oregon. Transportation Research Record 1780: 33-42.

[14] Handy, S. (1992): How Land-Use Pattern Affect Travel Patterns: A Bibliography. CPL Bibliography. - Council of Planning Librarians, Chicago.

[15] Hou, Q. H., Wang, W. H. (2016): Interactive control of land use intensity for hierarchical regulatory plan. - Journal of Computational and Theoretical Nanoscience 13(2): 12831290.

[16] Hou, Q. H., Yang, S. L., Fang, Y. N., Zhang, L. D. (2017): Research on the application of AVC theory in data analysis of urban affairs and planning method. - Cluster Compute 6: $1-14$. 
[17] Hou, Q. H., Zhang, X., Li, B., Zhang, X. Q., Wang, W. H. (2018): Identification of lowcarbon travel block based on GIS hotspot analysis using spatial distribution learning algorithm. - Neural Computing and Applications 3: 1-11.

[18] Huang, J. N., Du, N. R., Liu, P. (2013): An exploration of land use mix around residence and family commuting caused carbon emission: a case study of Wuhan City in China. International Urban Planning 28(2): 25-30.

[19] Kockelman, K. M. (1997): Travel behavior as a function of accessibility, land-use mixing, and land-use balance: evidence from the San Francisco Bay area. Transportation Research Record 1607: 116-125.

[20] Levinson, D. M., Kumar, A. (1997): Density and the journey to work. - Growth and Change 28(2): 147-172.

[21] Liu, C., Qing, S. (2011): An empirical analysis of the influence of urban form on household travel and energy consumption. - Computers Environment and Urban Systems 35(5): 317-357.

[22] Liu, J. J., Wang, W., Cheng, L. (2010): Effect of land-use on resident travel mode in compact single center city. - Journal of Transport Information and Safety 28(2): 74-78.

[23] Long, W., Zhang, Y., Cui, C. Y. (2012): Identifying commuting pattern of Beijing using bus smart card data. - Acta Geographica Sinica 67(10): 1339-1352.

[24] Ma, J., Chai, Y. W., Liu, Z. L. (2011): The mechanism of $\mathrm{CO}_{2}$ emissions from urban transport based on individuals' travel behavior in Beijing. - Acta Geographica Sinica 66(8): 2023-1032.

[25] Ma, J., Liu, Z. L., Chai, Y. W. (2013): Urban form and carbon emissions from urban transport: based on the analysis of individual behavior. - Urban Planning International 28(2): 19-24.

[26] Maat, K., Timmermans, H. (2009): Influence of the residential and work environment on car use in dual- earner households. - Transportation Research Part A: Policy and Practice 43(7): 654-664.

[27] Mao, J. X., Yan, X. P. (2002): The mutual relationship between urban transport system and land use in China. - Urban Planning Forum (4): 34-37.

[28] Mao, J. X., Yan, X. P. (2005): Impacts of urban transport system on urban land useCase Study of Guangzhou City. - Scientia Geographica Sinica 28(3): 3353-3360.

[29] Mao, J. X., Yan, X. P., Wang, F. (2004): The influence of high-density land development on traffic system - with Guangzhou as an example. - Planners 30(12): 99-104.

[30] Newman, P. W. G., Kenworthy, J. R. (1996): The land use-transport connection: an overview. - Land Use Policy 13(1): 1-22.

[31] Pan, H. X. (2010): Urban spatial structure towards low carbon new urban transport and land use model. - Urban Development Studies 17(1): 40-45.

[32] Pan, H. X., Shen, Q., Zhang, M. (2009): Influence of urban form on travel behavior in four neighborhoods of Shanghai. - Urban Studies 44(2): 274-294.

[33] Qin, B., Tian, H. (2013): The impact of community spatial form on residents' carbon emissions. - China Urban Planning Society: Urban Age, Collaborative Planning. Proceedings of 2013 China Urban Planning Annual Conference, pp. 613-623.

[34] Susan, H. (1996): Urban form and pedestrian choices: study of Austin neighborhoods. Transportation Research Record: Journal of the Transportation Research Board 1552: 135-144.

[35] Tana., Chai, Y. W., Guan, M. B. (2015): The relationship between the built environment and car travel distance on weekdays in Beijing. - Acta Geographica Sinica 75(10): 16751685 .

[36] Tu, J. Z., Ma, D. L. (2018): A spatial economics perspective on convergence research of carbon emissions performance in China. - International Journal of Heat and Technology 36(3): 962-972. 
[37] Wang, D. G., Chai, Y. V. (2009): The jobs-housing relationship and commuting in Beijing, China: the legacy of Danwei. - Journal of Transportation. Geography 17(1): 3038.

[38] Xiao, Y. (2011): Preliminary Study on Urban Block Planning under Green Scale. Huazhong University of Science and Technology, Wuhan.

[39] Zhang, X., Liu, Y., Hou, Q. H. (2018): Characteristics of built environment in low-carbon travel block based on GIS hotspot technology. - Journal of Chang' an University Natural Edition 38(1): 89-97.

[40] Zhou, Y., Qian, C. Y. (2014): Neighborhood functions and layout for low carbon transportation. - Planners 30(9): 82-87.

[41] Zhou, S. H., Yang, L. J. (2005): The influence of urban land use intensity on urban traffic. - Urban Planning Forum (2): 75-80. 